\title{
Management of Vancomycin-Resistant Enterococci - a Paradigm
}

\author{
Georg Maschmeyer \\ Abteilung Hämatologie und Onkologie, Medizinische Klinik, Klinikum Ernst von Bergmann, Potsdam, Germany
}

Vancomycin-resistant enterococci (VRE) have spread among diverse groups of hospitalized patients since the early 1990's [1]. The first reports on outbreaks in hematology and oncology wards by Montecalvo et al. [2] or Timmers et al. [3] indicated a threatening scenario of fatal infections due to Enterococcus faecium completely non-susceptible to any potent antimicrobial agent available for clinical use, including the glycopeptide antibiotics. It has been hypothesized that the inappropriate clinical use of vancomycin and the preferential use of cephalosporins and fluoroquinolones were the main causes for the rapid spread of VRE in US hospitals, however, a convincing correlation between hotspots of these practices and a sharp increase in the emergence of VRE has never been demonstrated. Considering the link between the genes encoding macrolide resistance and glycopeptide resistance as well as the widely used administration of macrolide or glycopetide antibiotics for growth promotion in pigs or poultry in many industrialized countries in the 1990 's, it has become clear that only a joint effort of epidemiologists, clinicians, infection control experts, regulatory agencies, politics and stock-farmers would have the prospect of being successful in the management of this menace.

It has indeed been demonstrated that the ban of avoparcin (a glycopeptide antibiotic), avilamycin, virginiamycin (a streptogramin compound), tylosin (a macrolide) and quinolones from animal-breeding has resulted in dramatic reductions in the prevalence of glycopeptide-resistant pathogens from poultry and pigs in Denmark [4], Italy [5], and elsewhere. Of note, avoparcin had never been approved for use in animal-breeding in the USA. At the same time, the oral administration of a non-absorbable antimicrobial prophylaxis consisting of gentamicin, vancomycin, and nystatin ('GVN') has been routinely used in neutropenic cancer patients in the USA in the 1970's and 1980's, however, hematology and oncology wards have not been the preferred locations for VRE outbreaks. Therefore, a simplistic approach is of no benefit in the discussion of causes for and management of VRE and other threatening outbreaks. In clinical practice, the prudent use of antibiotics along with increased alertness and functioning microbiological surveillance will provide the basis for the prevention of unperceived outbreaks of VRE or extend-spectrum beta lactamase producing pathogens (ESBL).

These considerations, however, are in contrast with the development of clinical working conditions in these days. Overwhelming bureaucratic duties, drastic financial restrictions and the compulsion to focus on career-promoting research topics retain hospital doctors from thorough engagement in 'marginal' issues related to microorganisms exhibiting unusual susceptibility patterns. Investigator-initiated studies involving humans and the use of pharmaceutical agents have become subject to legal and fiscal pre-conditions, which are impossible to fulfill outside professional research organizations and without potent sponsors. Therefore, the doors are wide open for statements, regulations or recommendations that are not backedup by convincing data. And as far as these recommendations affect common clinical attitudes, the risk of being ignored is higher than in the past. Strict infection control measures such as isolation of patients in single rooms, barrier nursing, multifocal sampling of material for detailed microbiological workup, temporary use of expensive antimicrobial agents replacing the cheapest available cephalosporins, or taking time to put together relevant clinical data and microbiological findings are troublesome for streamline, DRG-oriented patient management being propagated today.

Therefore, the effort taken by the authors of the paper entitled 'Outbreak of vancomycin-resistant enterococci in a haematological oncology ward and hygienic preventive measures' [6] in this issue of OnKOLOGIE deserve applause for their multidisciplinary approach to overcome two consecutive outbreaks of VRE in their tertiary care hospital. They are in line with recommendations from other institutions supporting strict infec-

\begin{tabular}{ll}
\hline KARGER & @ 2005 S. Karger GmbH, Freiburg \\
Fax +497614520714 & Accessible online at: \\
$\begin{array}{l}\text { E-mail Information@Karger.de } \\
\text { www.karger.com }\end{array}$ & www.karger.com/onk \\
&
\end{tabular}

Prof. Dr. med. Georg Maschmeyer

Abteilung Hämatologie und Onkologie, Medizinische Klinik

Klinikum Ernst von Bergmann

Charlottenstr. 72, 14467 Potsdam, Germany

Tel. +49 331 241-6001, Fax -6000

E-mail gmaschmeyer@klinikumevb.de 
tion control procedures to combat VRE outbreaks [7]. It would be highly desirable to co-operate in a similar way to combat a far more life-threatening infection killing the majority of our patients with acute leukemias or undergoing allogeneic stem cell transplantation - invasive aspergillosis. The release of billions of fungal spores from uncontrolled hospitalbuilding construction work, fire-proof materials, elevators, removal of dust and leaves by portable motorized blasts, and other sources, along with the lack of support for clinical studies on the use of preventive measures is another clinical battlefield for which a joint effort such as that of the authors of the VRE paper in this issue of ONKOLOGIE would be urgently required.

\section{References}

1 Gordts B, van Landuyt H, Leven M, Vandamme P, Goossens H: Vancomycin-resistant enterococci colonizing the intestinal tract of hospitalized patients. J Clin Microbiol 1995;33:2842-2846.

2 Montecalvo MA, Horowitz H, Gedris C, Carbonaro C, Tenover FC, Issah A, Cook P, Wormser GP: Outbreak of vancomycin-, ampicillin-, and aminoglycoside-resistant Enterococcus faecium in an adult oncology unit. Antimicrob Agents Chem-other 1994;38:1363-1367.

-3 Timmers GJ, van der Zwet WC, Simoons-Smit IM, Savelkoul PH, Meester HH, Vandenbroucke-Grauls CM, Huijgens PC: Outbreak of Vancomycin-resistant Enterococcus facium in a haematology unit: Risk factor assessment and successful control of the epidemic. Br J Haematol 2002;116:826-833.

4 Aarestrup FM, Seyfarth AM, Emborg HD, Pedersen K, Hendriksen RS, Bager F: Effect of abolishment of the use of antimicrobial agents for growth promotion on occurrence of antimicrobial resistance in fecal enterococci from food animals in Denmark. Antimicrob Agents Chemother 2001;45:2054-2059.

5 Pantosti A, Del Grosso M, Tagliabue S, Macrì A, Caprioli A: Decrease of vancomycin-resistant enterococci in poultry meat after avoparcin ban. Lancet 1999;354:741-742.

6 Knoll M, Daeschlein G, Okpara-Hofmann J, Klare I, Wilhelms D, Wolf HH, Borneff-Lipp M: Outbreak of vancomycin-resistant enterococci in a haematological oncology ward and hygienic preventive measures. Onkologie 2005;28: DOI: $10.1159 / 000084061$.

7 Padiglione AA, Wolfe R, Grabsch EA, Olden D, Pearson S, Franklin C, Spelman D, Mayall B, Johnson PDR, Grayson ML: Risk factors for new detection of vancomycin-resistant enterococci in acute-care hospitals that employ strict infection control procedures. Antimicrob Agents Chemother 2003;47;2492-2498. 